\title{
Considerations in the development of a follow-up exploratory quantitative design for student's motivation regarding to work industry-related activities in higher engineering education
}

\author{
Panagiotis Pantzos \\ Dept. of Learning in \\ Engineering Sciences \\ KTH Royal Intitute of \\ Technology \\ Stockholm, Sweden \\ pantzos@kth.se
}

\author{
Lena Gumaelius \\ Dept. of Learning in \\ Engineering Sciences \\ KTH Royal Intitute of \\ Technology \\ Stockholm, Sweden \\ lenagu@kth.se
}

\author{
Jeffrey Buckley \\ Dept. of Learning in \\ Engineering Sciences \\ KTH Royal Institute of \\ Technology \\ Stockholm, Sweden \\ Faculty of Engineering \& \\ Informatics \\ Athlone Institute of Technology \\ Co. Westmeath, Ireland \\ jbuckley@kth.se
}

\author{
Arnold Pears \\ Dept. of Learning in \\ Engineering Sciences \\ KTH Royal Intitute of \\ Technology \\ Stockholm, Sweden \\ arnold.pears@ieee.org
}

\begin{abstract}
This Work in Progress paper describes considerations relative to the development of a follow-up exploratory quantitative design for examining student motivation in higher engineering education. The intent of the current work is to build on the outcomes of a previous qualitative study exploring the perceptions of students with regard to work industry-related activities included as part of their formal study experience in Swedish university settings. In the follow-up study design discussed in this paper we focus on a quantitative approach to assessing the impact of such experiences on student motivation. Findings from our previous study indicate both that how these different work industryrelated activities are conducted and how the different relationships that are present can effect students' motivation for learning in tertiary engineering education. However, while the earlier study provides understanding of which scenarios can affect student motivation, there is a need to consider relative effect sizes. To address this issue in this paper, we present considerations for a survey design and discuss the determination of population and sample size and study variables for a preliminary survey instrument. We also propose methods with which to establish validity and reliability, as well as presenting a data analysis plan. At this juncture, the development of a follow-up exploratory quantitative study will contribute to a better understanding of students' perceptions about work industry-related activities which is currently a prime concern in higher engineering education, providing guidelines for a more critical planning of these activities in the future.
\end{abstract}

Keywords-follow-up exploratory quantitative design, engineering education, student motivation

\section{INTRODUCTION}

Qualitative research studies typically lead to inductively generated theories and themes that emerge from subjective interpretations and are derived from data that are revealed within a specific context. From a mixed methods perspective, the question then is how these findings can be extended with the supplementary strengths of quantitative methods. In other words, what it means for a quantitative follow-up study to enhance the findings from a core qualitative study. The fundamental principle of a quantitative follow-up study is that the researcher has goals that go beyond the usual stopping point for a stand-alone qualitative study. In fact, the main scope is to increase the credibility of the previous qualitative findings by presenting that they can be converted into substantial measures that perform in predictable practices. Furthermore, through conducting a quantitative follow-up study, greater generality can be demonstrated [1]. Specifically, an exploratory sequential design is developed in which firstly, the researcher creates an instrument that builds on the qualitative findings and is used in the subsequent quantitative data collection [2], and secondly the exploratory quantitative follow-up study is conducted [3].

The purpose of this paper is to present the development of an exploratory follow-up quantitative study design for use in higher engineering education based on previous qualitative work [4]. The design is based on the premise that appropriate instruments are not available in advance. The previous qualitative research study explored the variability of students' perceptions of the nature of work industry-related activities that they encountered within engineering education in two large research-intensive Swedish universities, and given an understanding of which scenarios can affect student motivation there is a need now to consider relative effect sizes [5]. At this juncture, the conduction of a follow-up quantitative study is going to contribute to a better understanding of students' perceptions about work industryrelated activities which is a prime concern in higher engineering research and education today, exploring the phenomenon in depth through measuring the prevalence of its dimensions, and contributing to the critical planning of these activities in the future. The findings from this previous study provided insights into how different work industryrelated activities, and different relationships between actors involved in those activities, can affect students' motivation for studying and continued learning in higher engineering education.

\section{PREVIOUS QUALITATIVE STUDY FINDINGS}

The previous study explored what impact industry-related activities have on students' motivation when studying on different engineering programmes. Based on this, the following research questions were posed: a) what industryrelated activities did the sample of engineering students 
engage with during their studies, and b) how did the students perceive these industry-related activities to affect their motivation to study and learning. An explorative, qualitative strategy was employed. Semi-structured interviews were conducted in which questions and sub-questions were asked representing thematic categories so that the research questions were addressed. The sample of the study included 18 students of both Swedish and international nationalities who were studying on different undergraduate and masters' engineering programmes at two large, research intensive
Swedish universities. Subsequently, an inductive analysis was carried out on the transcribed data using the NVivo software. The inductive thematic analysis process that was applied derived several key concepts. These themes are considered to be crucial in determining students' understandings on how the students perceived these industryrelated activities to affect their motivation to study and for learning. The findings of the previous qualitative study are illustrated in Table I. The new instrument, which will be considered in this paper builds on these findings.

TABLE I. QuALiTATIVE Findings of PREVIOUS STUdy-MOTIVATION FACTORS OF WORK-INDUSTRY RELATED ACTIVITIES

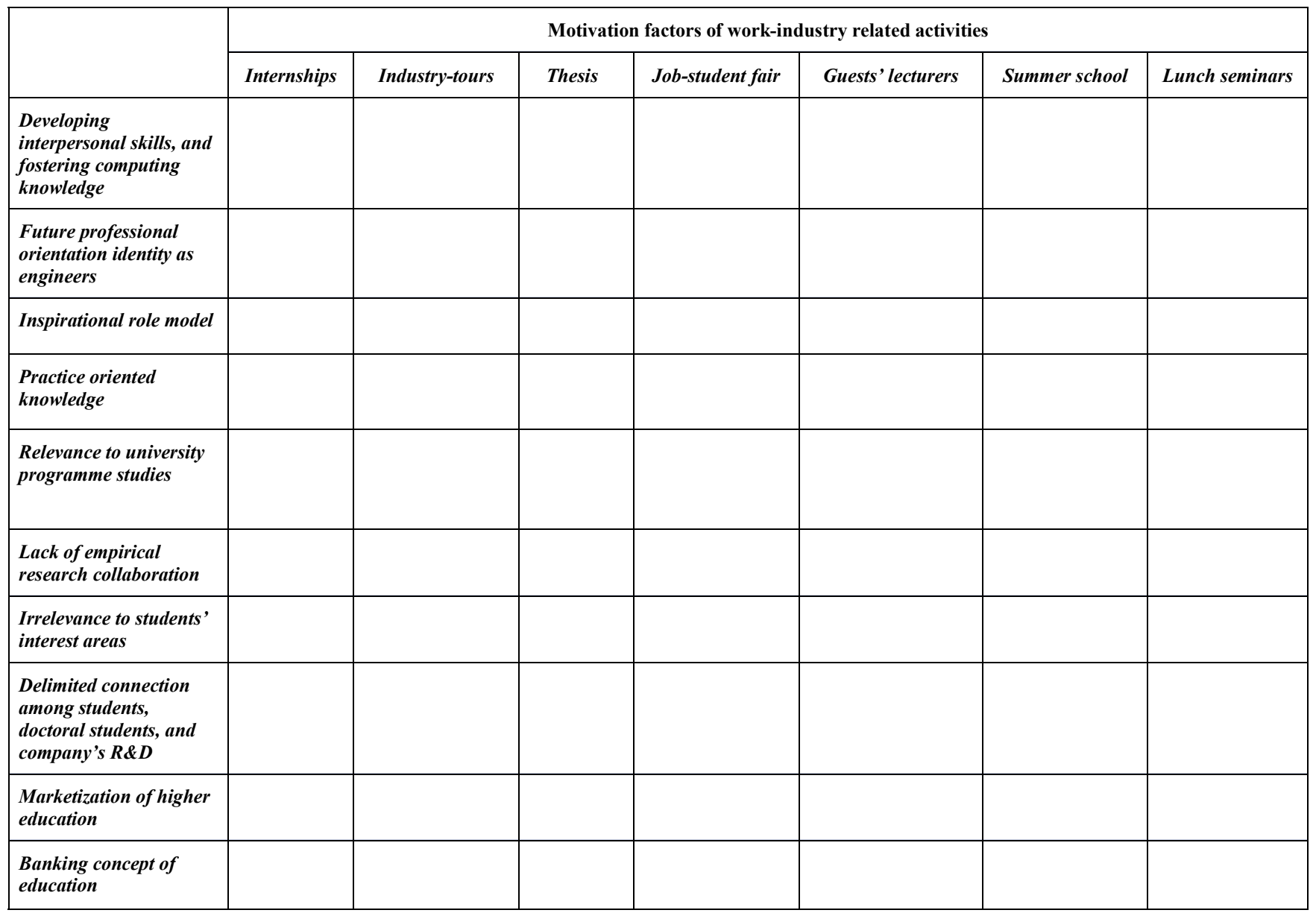

\section{STUDY DESIGN}

\section{A. Research Design}

In this study a non-experimental research design is proposed. More specifically, this paper develops a correlational research survey design. The aim of a correlational study is to explore and measure relationships between two or more variables. Correlational research in education investigates abilities, conditions, or traits that corelate, or covary, with each other [6]. A correlational study tries to examine whether and to what degree a statistical relationship exists between two or more variables. Such a study is commonly used to describe or measure prevailing conditions or something that happened in the past [7]. In fact, the proposed study design will involve measuring if there is a positive or negative relationship - and if so, how strong between the students' experiences on different kind of work industry-related activities and their motivation for learning and studying in higher engineering education. It is important to state that, at the time the researcher would collect data on these variables (i.e., "student beliefs on work industry-related activities" and "student motivation"), they have already occurred. In addition, it is ordinarily the case in a correlational study that the variables measured appear naturally. In the present study, students would "naturally" participate on several work industry-related activities in engineering education and they would "naturally" be affected in regards to their motivation for learning and studying. Therefore, when a correlational research design is used, there is no experimental manipulation of any of the conditions being measured in the study. 


\section{B. Identification of the topic/problem to be studied}

As a correlational study is designed with an aim to measure relationships between variables and/or to test hypotheses about predictions, the variables should be selected in such a way that some logical rationale exists [8], [9]. In this case, the follow-up quantitative study examines the following research question: What is the relationship between different work industry-related activities and students' motivation factors of work-industry related activities?

\section{Identification and Selection of participants}

The population for the follow-up quantitative study will be both undergraduate students and masters' students who are pursuing five-year engineering programmes in Sweden. In Sweden, a master's program consists of a two-year program, the final two years of a five-year programme, containing both coursework and a Master's research thesis during the final semester. The participating students should meet the criteria of having encountered work industry-related activities during their study time. Both Swedish and international students who take part in the study should be either at the end of the third year of their undergraduate engineering studies, i.e., just about to commence studying at master's level, or in the first or the second year of their master's studies. The reason for selecting these years' is that all of the students would have participated in several work industry-related activities since these are included in their programmes of study.

In Swedish tertiary engineering education, the offered study programmes are mainly focusing on both professional practice and research in its teaching and learning [10]. Based on the aim of the study and the above participant criteria, the researcher plans to distribute the survey through university administrations, primarily to the departments that their programmes emphasising connections to industry.

Finally, for a correlational study, an appropriate sample size is needed in order to achieve the necessary $(80 \%)$ statistical power [9] and in this case, representation. When sample size increases, the standard error of the mean gets reduced. A full power analysis will be conducted once the quantitative instrument is development so that it can accurately reflect the included variables.

\section{Determination of the mode of data collection}

Due to the sequential approach, the instrument development of this study is be based on the emergent themes and specific statements acquired from participants in the previous initial qualitative data collection. In the next stage, these statements will be used as specific items and the themes for scales to create a survey instrument that is grounded in the views of the participants [11]. Next, validity of items will be examined through pilot work. The most appropriate method currently is a web-based survey for collecting data from students who are engaged in higher education due to the current COVID-19 pandemic and from a logistical perspective [12]. A Likert-type scale survey instrument will be distributed to potential respondents via email [6] and this follow-up study will be developed on software such as SurveyMonkey or Qualtrics since these are considered to be the most common and user-friendly tools for survey creation. The online questionnaire will be designed according to previous qualitative study themes as presented before in Table I. Additionally, the questions will be developed into the following main conceptual categories: how do students' work industry-related activities effect/impact on students' motivation to studying and learning in higher engineering education; student motivation meaning; student's perceptions during their studies in higher engineering education; motivational factors for continuing studying; motivational factors for learning (while their studies). Finally, a pilot test on a small cross-sectional population sample will be run to specify if any revisions should be made before actual data collection occurs [9]. Through this pilot study the reliability will be ensured and also it will guarantee the correctness of the instrument, the language of instruction, and acceptability among the participants.

\section{E. Collection of Data}

Data will be gathered in a manner appropriate to the variables of interest. Furthermore, it will be collected through the administration of the web-based survey instrument. Following this, the collected data will be analyzed within appropriate statistical software, such as SPSS or RStudio.

\section{F. Data Analysis}

The quantitative data of this exploratory follow-up quantitative study will be analyzed by examining descriptive statistics and ordinal logistic regression including odds ratios as effect sizes [13]. Additionally, according to Bryman statistical inference, which is "the process of inferring findings from a probability sample to the population from which it was selected" [13: 346] will be explored. The findings of the previous qualitative study are now going to be measured by means of ordinal scales due to the nature of the variables. When it is necessary to control feasible confounding factors or when several factors need to be taken into consideration, multivariate analyses for ordinal data such as multinomial logistic regression will be conducted. Finally, it is important to mention that effect sizes will also be tested. According to Durlak (2009), the effect sizes statistics "provide information about the magnitude and direction of the difference between two groups or the relationship between two variables" [19: 917]. Specifically, an effect size can be characterised such as a difference between means, a correlation, a percentage, odds ratio or any other meaningfully quantified difference or association [16].

\section{G. Answering Research Questions and Drawing Conclusions}

The results of the data analyses should allow the guiding research questions to be answered, or the hypotheses to be addressed, for the study. Inferences can be drawn such as to what extent the relationship between the variables of interest within the population occurs and appropriate associational, but not causal, conclusions about the study can be asserted. More specifically, the main research question of what is the relationship between different work industry-related activities and students' motivation factors of work-industry related activities will be answered through sub-questions and objectives of the study, for instance to what extent are industry tours, career fairs and guest lectures associated misaligned with students' interest areas? 


\section{VALIDITY AND RELIABILITY OF THE RESEARCH INSTRUMENT}

Validity gives meaning to how well the collected data applies to the actual area of exploration [17]. According to Field, validity primarily concerns the ability to "measure what is intended to be measured" [18]. On the other hand, reliability corresponds to the extent to which a measurement of a phenomenon gives consist and stable results [19]. Additionally, reliability is concerned with repeatability. For instance, a test or scale is considered to be reliable if repeated measurements made by it under steady conditions will provide the same result [20]. In order for the consistency of all parts of a measuring instrument to be determined, testing for reliability is required [21]. A scale is supposed to have high internal consistency if the items of a scale "hang together" and measure the same form [21], [22]. The Cronbach's Alpha coefficient will be used as a measure of internal consistency since Likert-type scales will be made use of within this study [22], [23]. Moreover, it is suggested that reliability should be equal to or above 0.60 for an exploratory study [24]. Finally, Durlak [15] has suggested that a comparison of the validity components, which provides the most well accepted techniques that need to be conducted for validity and reliability of the research instrument. Some of these techniques, which are illustrated below in Table II, will be applied to this follow-up quantitative study as well.

TABLE II. VALIDITY \& RELIABILITY COMPONENTS OF INSTRUMENT

\begin{tabular}{|c|c|c|c|}
\hline \multicolumn{4}{|c|}{ Comparison of Validities } \\
\hline $\begin{array}{c}\text { Validity } \\
\text { Component } \\
\end{array}$ & Definition & Type & $\begin{array}{l}\text { Technique } \\
\text { Suggested }\end{array}$ \\
\hline $\begin{array}{l}\text { Construct } \\
\text { Discriminant } \\
\text { validity }\end{array}$ & $\begin{array}{l}\text { The extent that } \\
\text { measures of } \\
\text { different } \\
\text { constructs } \\
\text { diverge or } \\
\text { minimally } \\
\text { correlate with } \\
\text { one another }\end{array}$ & Mandatory & $\begin{array}{l}\text { MTMM; } \\
\text { PCA; CFA; } \\
\text { PLS AVE; } \\
\text { Q-sorting }\end{array}$ \\
\hline $\begin{array}{l}\text { Construct } \\
\text { Convergent } \\
\text { validity }\end{array}$ & $\begin{array}{l}\text { The extent that } \\
\text { different } \\
\text { measures of the } \\
\text { same construct } \\
\text { converge or } \\
\text { strongly } \\
\text { correlate with } \\
\text { one another }\end{array}$ & Mandatory & $\begin{array}{l}\text { MTMM; } \\
\text { PCA; CFA; } \\
\text { Q- sorting }\end{array}$ \\
\hline $\begin{array}{l}\text { Criterion } \\
\text { Predictive } \\
\text { Validity }\end{array}$ & $\begin{array}{l}\text { The extent that } \\
\text { a measure } \\
\text { predicts another } \\
\text { measure }\end{array}$ & Mandatory & $\begin{array}{l}\text { Regression } \\
\text { Analysis, } \\
\text { Discriminant } \\
\text { Analysis }\end{array}$ \\
\hline $\begin{array}{l}\text { Criterion } \\
\text { Concurrent } \\
\text { Validity }\end{array}$ & $\begin{array}{l}\text { The extent that } \\
\text { a measure } \\
\text { simultaneously } \\
\text { relates to } \\
\text { another measure } \\
\text { that it is } \\
\text { supposed to } \\
\text { relate }\end{array}$ & Mandatory & $\begin{array}{l}\text { Correlation } \\
\text { Analysis }\end{array}$ \\
\hline $\begin{array}{l}\text { Criterion } \\
\text { Postdictive } \\
\text { Validity }\end{array}$ & $\begin{array}{l}\text { The extent that } \\
\text { a measure is } \\
\text { related to the } \\
\text { scores on } \\
\text { another, already } \\
\text { established in } \\
\text { past }\end{array}$ & Mandatory & $\begin{array}{l}\text { Correlation } \\
\text { Analysis }\end{array}$ \\
\hline $\begin{array}{l}\text { Reliability } \\
\text { Internal }\end{array}$ & $\begin{array}{lr}\text { The extent to } \\
\text { which }\end{array}$ & Mandatory & $\begin{array}{l}\text { Cronbach's a; } \\
\text { correlations; }\end{array}$ \\
\hline
\end{tabular}

\begin{tabular}{|l|l|l|l|}
\hline consistency & $\begin{array}{l}\text { measurement of } \\
\text { a phenomenon } \\
\text { provides stable } \\
\text { and consist } \\
\text { result }\end{array}$ & & SEM \\
reliability \\
coefficients
\end{tabular}

\section{ETHICAL CONSIDERATIONS WHEN CONDUCTING RESEARCH}

Society's expectation of greater accountability when conducting research brings an increased and broadened level of attention on its ethical conduct (the actions that are personal, professional, and during research activity) [25][27]. One of the fundamentals of ethical research is informed consent [28]. Participants of the study need to be fully informed of the nature of the research and what (if any) consequences there could come from their participation at the outset. The participants will need to sign an explicit, active, consent form to taking part with the research, in which understanding their rights to access to their information and the right to withdraw anytime and at any point are included [14].

An important concern is the degree to which invasion of privacy can be accepted, consequently it is critical that the identity of the participants is anonymous or confidential. Specifically, assurances must be extended beyond protecting participants' names, as well as, the avoidance of using selfidentifying information and statements need to be considered. In fact, during the whole research process, anonymity and confidentiality should be provided for protecting the participants from potential harm. More specifically, participant anonymity will be respected and the participant's identity will be unknown to the researcher in the follow-up quantitative study, since it is an anonymous survey. Participant confidentiality was respected in the previous qualitative study, since the data collected through the interviews was de-identified and the identity of informants was kept confidential [14].

\section{CONCLUSION}

Designing a research methodology and appropriate choice of methods in advance should be considered as an important aspect of engineering education research. With pre-registration, the researcher specifies their hypotheses and analysis plan in advance of data collection [29]. Research context, research questions, and the researcher capability must always be considered. Specifically, this paper describes a number of considerations underpinning the development of a follow-up exploratory quantitative study in a comprehensive way. This development connects the previous qualitative phase to the subsequent quantitative strand of the study. The follow-up study will build on the primal findings of the qualitative phase by developing an instrument, identifying variables, or referring propositions for investigating based on an emergent theoretical framework. Next, the study will implement the quantitative strand to test the salient variables using the developed instrument with a new sample of participants in an ethical manner. What is critical is that the research methodology and methods align with the aim of the research and the nature of the research questions. Finally, the results of the study will be interpreted with consideration for what ways and to what extent they can be generalized or expand on the primary qualitative findings and with an avoidance of external validity threats. 


\section{REFERENCES}

[1] D. Morgan, Integrating qualitative and quantitative methods. 55 City Road. London: SAGE Publications, 2014.

[2] J. W. Creswell, M. D. Fetters, and N. V Ivankova, "Designing a mixed methods study in primary care," Ann. Fam. Med., vol. 2, pp. 7-12, 2004.

[3] D. L. Morgan, "Practical Strategies for Combining Qualitative and Quantitative Methods: Applications to Health Research. Qualitative Health Research,” vol. 8, pp. 362-376, 1998.

[4] P. Pantzos, L. Gumaelius, J. Buckley, and A. Pears, "On the role of industry contact on the motivation and professional development of engineering students," in 2019 IEEE Frontiers in Education Conference (FIE), 2019, pp. 1-8.

[5] J. W. Creswell, P. Clark, V. L., M. L. Gutmann, and W. E. Hanson, "Advanced mixed methods research designs," in Handbook on mixed methods in the behavioral and social sciences, A. Tashakkori and C. Teddlie, Eds. Thousand Oaks, CA: Sage Publications, 2003, pp. 209-240.

[6] C. A. Mertler, Introduction to educational research. CA: Sage Publications, 2016.

[7] A. P. Johnson, A short guide to action research (3rd ed.). Boston: Pearson, 2008

[8] J. R. Fraenkel, N. E. Wallen, and H. Hyun, How to design and evaluate research in education (8th ed.). Boston, MA: McGrawHill, 2012.

[9] L. R. Gay, G. E. Mills, and P. W. Airasian, Educational research: Competencies for analysis and applications (9th ed.) Upper Saddle River. NJ: Merrill, 2009.

[10] M. Magnell, "Academic staff on connections to professional practice and research in engineering education: a discourse analysis," Eur. J. Eng. Educ., 2020

[11] J. Creswell, Research design: Qualitative, quantitative, and mixed methods approaches ( $3 r d$ ed.). Thousand Oaks, CA: Sage, 2009.

[12] L. Cohen, L. Manion, and K. Morrison, Research Methods in Education. 2010

[13] J. W. Creswell and V. L. Plano Clark, Designing and conducting mixed methods research. Thousand Oaks, CA: Sage, 2007.

[14] A. Bryman, Social Research Methods, 5th ed. Oxford University
Press, USA, 2016.

[15] J. A. Durlak, "How to select, calculate, and interpret effect sizes," J. Pediatr. Psychol., vol. 34, pp. 917-928, 2009.

[16] T. Vacha-Haase and B. Thompson, "How to estimate and interpret effect sizes," J. Couns. Psychol., vol. 51, pp. 473-481, 2004.

[17] P. Ghauri and K. Gronhaug, Research Methods in Business Studies. FT/Prentice Hall: Harlow, 2005.

[18] A. P. Field, Discovering Statistics Using SPSS. Sage Publications Inc, 2005 .

[19] E. G. Carmines and R. A. Zeller, Reliability and Validity Assessment. CA, SAGE: Newbury Park, 1979.

[20] C. A. Moser and G. Kalton, Survey methods in social investigation. Gower: Aldershot, 1989.

[21] S. W. Huck, Reading Statistics and Research. Allyn \& Bacon: United States of America, 2007

[22] J. Robinson, Triandis theory of interpersonal behaviour in understanding software privace behaviour in the South African context. University of the Witwatersrand: Masters degree, 2009.

[23] B. E. Whitley, Principals of Research and Behavioural Science. McGraw-Hill: Boston, 2002.

[24] D. Straub, M.-C. Boudreau, and D. Gefen, "Validation guidelines for IS positivist research,” Commun. Assoc. Inf. Syst., vol. 13, pp. 380-427, 2004

[25] K. D. Haggerty, "Ethics creep: Governing social science research in the name of ethics," Qual. Sociol., vol. 27, no. 4, pp. 391-414, 2004

[26] V. Held, The ethics of care: Personal, political, and global. New York, NY: Oxford University Press, 2006.

[27] K. E. Zegwaard, M. Campbell, and T. J. Pretti, "Professional identities and ethics: The role of work-integrated learning in developing agentic professionals," in Work-integrated learning in the 21st century: Global perspectives on the future, T. Bowen and M. T. B. Drysdale, Eds. Bingley, UK: Emerald Publishing Limited, 2017, pp. 145-160

[28] N. K. Denzin and Y. S. Lincoln, The SAGE Handbook of Qualitative Research. Thousand Oaks, CA: Sage, 2011.

[29] C. S. Peirce, "A theory of probable inference," in Studies in logic, C. S. Peirce, Ed. Boston: Little \& Brown, 1883, pp. 126-181. 